\title{
MAKNA KaOs Islami Distro Kalam
}

\section{(STUdi FenOMENOLOGi Tentang KaOS ISLAMi Distro KaLAM BANDUNG DI Kalangan Pemakai)}

\author{
Adi Muhammad Ramadhan \\ Program Studi Magister Ilmu Komunikasi Pascasarjana Universitas Islam Bandung \\ e-mail: adiebolang@gmail.com
}

\begin{abstract}
This research observed the meaning of an Islamic T-shirt Kalam Bandung Distro. Communication is the process of delivering a message from the communicator to the communicant either through the media or directly. Communication can be done through verbal or nonverbal. Nonverbal communication is a process of communication or delivery of messages through symbols, images and other things. Design of the T- shirt is one of the non-verbal communication, where there is no intention or message to be conveyed by the manufacturer to the buyer or user. Moreover, especially for islamic T-shirt where there must be a purpose that is either expected or desired T-shirt maker to the wearer. This study aims to obtain the overview of the meaning of the Islamic T-shirt Kalam Bandung Distro among the Users. This research used a qualitative method with phenomenological study. Phenomenology study used so that researchers can explore the experience of users in defining islamic T-shirt Kalam Bandung distro both in everyday life in private life or in social. Data collected by using observation, literature study, study the documentation, and in-depth interviews. The results showed that all the informants have a common motive in wearing this islamic T-shirt Kalam Distro, they were: Islamic motifs reminders (limiting ourselves), syiar motive or indirect propaganda and self-presentation motive. Motive reminders or self-limiting because the prime motive of the most enemies real and lasting is the him self, is one way that when wearing the T-shirt Kalam, the attitudes and hearts be limited to things that are evil. Motive symbols of Islam or proselytizing indirectly a motive advanced for wearing T-shirts Kalam then either intentionally or unintentionally public or to those who were around the wearer into reading or viewing the message content through existing designs on T-shirts Kalam, although the public or the public respond or ignored message content or design t-shirts Kalam itself, at least they noticed it. Self- motive presentation became complementary motives for becoming a pride characterized or showed in a modern islamic identity and did not come out of the social and cultural aspects in the general environment. The Meaning of T-shirts Islamic Kalam Distro is as the mean of controlling especially himself and generally to the public as general, and also the duty of the Prophet Muhammad to preach and spread the goodness of Islamic values.
\end{abstract}

Keywords: meaning, Islamic T-shirt, Kalam Distro.

Abstrak. Penelitian ini mengkaji tentang makna kaos islami distro Kalam Bandung. Komunikasi adalah proses penyampaian pesan dari komunikator kepada komunikan baik melalui sebuah media ataupun secara langsung. Komunikasi dapat dilakukan melalui verbal atau nonverbal. Komunikasi nonverbal merupakan proses komunikasi atau penyampaian pesan melalui lambang, gambar dan hal lainnya. Desain dalam kaos merupakan salah satu komunikasi nonverbal, dimana ada maksud atau ada pesan yang ingin disampaikan oleh pembuat kepada pembeli atau pemakai. Terlebih lagi khususnya untuk kaos islami dimana pasti ada suatu maksud yang baik yang diharapkan atau diinginkan pembuat kaos kepada pemakainya. Penelitian ini bertujuan untuk memperoleh gambaran mengenai Makna Kaos Islami 
Distro Kalam Bandung di Kalangan Pemakai. Penelitian ini menggunakan metode kualitatif dengan studi fenomenologi. Studi Fenomenologi digunakan agar peneliti dapat menggali pengalaman para pemakai kaos dalam memaknai kaos islami distro Kalam Bandung baik dalam kehidupan sehari-hari di kehidupan pribadinya ataupun di sosialnya. Teknik pengumpulan data dilakukan dengan menggunakan observasi, studi kepustakaan, studi dokumentasi, dan wawancara mendalam. Hasil penelitian menunjukkan bahwa semua informan memiliki kesamaan motif dalam mengenakan kaos islami distro Kalam ini yaitu motif pengingat (pembatas diri), motif syiar atau dakwah secara tidak langsung, dan motif presentasi diri. Motif pengingat atau pembatas diri merupakan motif utama dikarenakan musuh yang paling nyata dan abadi adalah diri sendiri, merupakan salah satu cara agar ketika memakai kaos Kalam tersebut maka sikap dan hati menjadi terbatasi terhadap hal-hal yang bersifat kejelekan. Motif syiar islam atau dakwah secara tidak langsung menjadi motif lanjutan karena dengan memakai kaos Kalam maka baik sengaja ataupun tidak sengaja publik atau orang yang ada di sekitar pemakai menjadi membaca atau melihat isi pesan melalui desain yang ada pada kaos Kalam, walaupun publik atau masyarakat menanggapi atau mangacuhkan isi pesan atau desain kaos Kalam itu sendiri, minimal melihatnya. Motif presentasi diri menjadi motif pelengkap karena menjadi suatu kebanggan mencirikan atau memperlihatkan identitas muslim secara modern dan tidak keluar dari aspek sosial dan budaya yang ada di lingkungan umum. Makna kaos islami distro Kalam sendiri adalah sarana dalam mengendalikan secara khusus diri sendiri dan umunya masyarakat luas serta melaksanakan tugas yang dibawa Nabi Muhammad SAW untuk berdakwah dan menyebarkan kebaikan nilai-nilai Islam.

Kata kunci: Makna, Kaos Islami, Distro Kalam.

\section{Pendahuluan}

Perkembangan bentuk busana telah mengalami kemajuan yang cukup pesat. Mulai dari penggunaan kulit kayu, kulit binatang hingga manusia akhirnya menemukan teknologi pembuatan kain yang pada awalnya yang masih sederhana yaitu dengan menggunakan alat bantu mesin, disinilah manusia mengenal busana dalam arti yang sesungguhnya.

Dalam persoalan pakaian antara penganut sistem kapitalis dan sistem Islam jelas berbeda. Dalam sistem kapitalis pakaian dianggap sebagai salah satu ungkapan kepribadian, sebagai unsur penarik lawan jenis dan karena itu memiliki nilai ekonomis. Bentuk tubuh seseorang apalagi wanita sangat berpengaruh terhadap makna kebahagiaan dan masa depan.

Adapun Islam menganggap

bahwa pakaian digunakan memiliki karakteristik yang sangat jauh dari tujuan ekonomis apalagi yang mengarah pada pelecehan penciptaan makhluk Allah. Melalui cara berpakaian yang Islami, sesungguhnya Allah juga berkehendak memuliakan manusia sebagai makhluk yang memang telah Allah ciptakan sebagai makhluk yang mulia. Sebaliknya dengan tidak mengikuti cara berpakaian sesuai yang dikehendaki Allah, menyebabkan kedudukan manusia jatuh.

Kita dalam berpakaian pasti mempunyai maksud tertentu dalam hal pemilihan jenis pakaian, warna pakaian, bahan pakaian serta motif yang ada pada pakaian tersebut. Baik dalam penggunaan sehari-hari ataupun dalam tuntutan sebuah profesi dalam pekerjaan, dalam suatu acara atau bahkan untuk memperlihatkan kepada orang lain apa yang ingin orang lain pandang dari pemilihan pakaian kita.

Pada awalnya, pemikiran untuk memproduksi baju dengan merek lokal timbul dari suatu komunitas tertentu, 
supaya berbeda dengan yang lain, di produksi terbatas dan untuk digunakan sendiri. Menyadari peluang yang timbul untuk menjual produk yang dihasilkan, mulailah produk ini dipasarkan ke konsumen lain walaupun jumlahnya tetap terbatas agar tidak pasaran.

Distro Kalam merupakan salah satu penggiat bisnis di bidang distro dari sekian banyaknya merek distro yang ada di kota Bandung. Distro Kalam sendiri masih dibilang anak baru di dunia bisnis distro yakni baru dibentuk pada tahun 2015. Distro kalam memiliki karakteristik sendiri yang khas yaitu membuat desain kaos distro yang berasaskan atau bernuansa Islami baik dalam bentuk tulisan-tulisan, gambargambar ataupun campuran dari keduanya sehingga akan menghasilkan suatu identitas tersendiri bagi pemakainya.

Pakaian apapun yang dipakai oleh manusia modern saat ini tidak hanya mengindikasikan bahwa hanya sekedar suatu kebutuhan untuk menutupi anggota tubuhnya tetapi sudah mengindikasikan terhadap suatu perasaan yang mewakili dirinya dalam mempresentasikan dirinya sendiri. Dari rasa perasaan yang terlibat itulah seorang manusia dapat memperlihatkan atau membuktikan tentang identitas dirinya akan karakteristik yang ditonjolkan dalam sebuah pakaian yang ia kenakan.

Hal ini mempengaruhi terhadap rasa percaya diri kita untuk berinteraksi dengan orang lain. Kita juga pernah tidak merasa percaya diri jika pakaian yang kita pakai tidak menunjukkan karakter kita sehingga akan mempengaruhi sosialisasi yang kita sedang lakukan.

Berdasarkan paparan di atas, maka selanjutnya penulis melakukan penelitian tentang "Makna Kaos Islami Distro Kalam”. Dengan menggunakan perspektif fenomenologi, penulis berupaya untuk mengetahui pemaknaan pemakaian kaos Islami distro Kalam di kalangan. Kaos Islami distro Kalam tersebut merupakan suatu bentuk komunikasi non verbal yang dituangkan melalui tulisan dan lambang-lambang atau simbol Islami.

\section{Metode}

Penelitian ini menggunakan metode kualitatif. Penelitian kualitatif menekankan kepada para penelitinya agar mementingkan penyelidikan yang sarat nilai. Artinya diperlukan penyelidikan secara mendalam agar mampu menjawab berbagai pertanyaanpertanyaan. Penelitian tentang "Makna Kaos Islami Distro Kalam Bandung di Kalangan Pemakai" lebih tepat dikaji dengan penelitian kualitatif, karena sangat sulit jika penelitian tersebut diukur secara matematis atau hitunghitungan berdasarkan angka-angka.

Dalam penelitian ini, salah satu yang ditekankan adalah bagaimana mengetahui dan mengkaji suatu motif dan makna serta pemahaman subjek penelitian pada objek penelitian tersebut.

Penelitian kualitatif menggali data secara alami apa yang sebenarnya terjadi di lapangan. Penelitian kualitatif bersifat empiris, yakni sesuai dengan kenyataan sebenarnya yang dapat diamati oleh panca indera manusia. Karena penelitian kualitatif datanya bersifat alami sesuai apa yang sebenarnya terjadi di lapangan, maka peneliti tidak boleh merekayasa data sesuai dengan keinginannya.

Penelitian ini menggunakan pendekatan fenomenologi dari Schutz. Dari penjelasan Schutz mengenai fenomenologi, penulis mengemukakan intisari atau beberapa poin-poin yang penting dalam pernyataannya tersebut. Pertama, bahwa peneliti sosial terlebih dahulu harus membuat interpretasi terhadap realitas yang diamati. 
Interpretasi adalah pemberian kesan, pendapat atau pandangan seseorang mengenai suatu realitas di dalam kehidupan sosial. Jadi, dalam fenomenologi Schutz, pemberian kesan, pendapat atau pandangan terhadap sebuah realitas adalah sesuatu yang dibolehkan, bahkan sebagai peneliti sosial, hal tersebut harus dilakukan.

Poin kedua yang bisa diambil dari pernyataan Schutz tersebut yakni bahwa dalam melakukan penelitian, peneliti harus menggunakan metode interpretif yang sama dengan orang yang diamati, sehingga peneliti bisa masuk ke dalam dunia interpretasi orang yang dijadikan objek penelitian. Jadi, dalam hal ini, peneliti diwajibkan memiliki tafsiran, pandangan atau pemberian kesan yang sama dengan orang yang diamati mengenai sebuah realitas.

Ketiga, yakni mengenai tindakan sosial yang merupakan bagian dari posisi peneliti dalam masyarakat. Artinya, tindakan sosial ini merupakan hal yang penting yang harus dilakukan peneliti untuk menjadi bagian dalam masyarakat yang diamati. Tindakan sosial tersebut bisa jadi hanya kamuflase atau peniruan dari tindakan orang lain yang ada di sekelilingnya. Peneliti menggunakan teknik ini untuk mendekati dunia kognitif objek penelitiannya. Artinya, dalam suatu penelitian sosial, peneliti harus mengedepankan aspek "kesamaan" dengan subjek penelitian. Tujuannya adalah untuk membuat rasa nyaman di antara subjek penelitian dengan peneliti, sehingga tidak membuat bias hasil penelitian. Ketika seseorang nyaman, ia akan menjadi dirinya sendiri, dan ketika ia menjadi dirinya sendiri inilah yang menjadi bahan kajian penulis.

Dalam fenomenologi Schutz juga terdapat model tindakan manusia yang dinamakan tipikasi. Tipikasi adalah ciri-ciri khusus yang dapat berupa tipe aktor, tipe tindakan, dan tipe kepribadian manusia yang terdapat dalam suatu kelompok atau organisasi kemasyarakatan. Artinya, dalam suatu kelompok atau organisasi terdapat anggota-anggota yang memiliki ciri-ciri khusus yang membedakannya satu dengan yang lainnya.

Dalam konteks penelitian penulis, aktor (kalangan Pemakai Sebagai Identitas Muslim) adalah pelaku yang memakai kaos Islami dari distro Kalam di kehidupan sosial ataupun pribadinya, dan juga dipakai untuk berbagai kegiatan aktivitas keseharian dari pemakai tersebut. Selain itu juga, pemakaian kaos Islami distro Kalam ini memunculkan motif presentasi diri pemakai kepada suatu masyarakat atau khalayak luas akan penampilannya. Hal tersebut akan membentuk makna atau pemahaman pemakai terhadap kaos Islami distro Kalam tersebut.

\section{Temuan dan Pembahasan}

\section{Profil Informan}

\subsection{Soni Sonjaya}

Soni Sonjaya lahir di Bandung pada tanggal 6 Februari 1973 merupakan turunan dari sang ba yang berasal dari Padang, dan ibu merupakan campuran batak-belanda-sunda. Soni memulai sekolahnya di SDN Sejahtera, SMPN 10 Bandung, SMAN 1 Bale endah lalu melanjutkan studi $\mathrm{S} 1$ di STHB dan melanjutkan pascasarjananya di Ilmu Komunikasi Universitas Islam Bandung (UNISBA).

\subsection{Heri Firmansyah}

Heri Firmansyah lahir di Bandung pada tanggal 23 Nopember 1980 yang memiliki cita-cita ingin menjadi artis ini merupakan lulusan dari Sekolah Dasar Negeri Centeh pada tahun 1997, melanjutkan ke SMP 
Negeri 37 Bandung dan merupakan alumni dari SMA PGII 1, lalu Heri Firmansyah melanjutkan ke Fikom UNPAD dengan mengambil jurusan Ilmu Komunikasi konsentrasi Broadcasting dan lulus pada tahun 2006.

\subsection{Agus Purwanto}

Agus Purwanto atau yang lebih sering dipanggil "Gaban" ini lahir di Bandung pada tanggal 1 Agustus 1970. Agus merupakan alumni dari SD Geger Kalong, SMP Kartika Chandra dan SMA PGRI 2 Bandung. Agus mempunyai seorang Ayah asli Surabaya dan Ibu dari Garut. Semenjak masuk ke tingkat SMP, Agus mulai menyukai dan bergelut di bidang momotoran bersama teman-temannya. Agus sewaktu kecil sering melakukan balap liar atau dalam istilah sundanya trek-trekan di daerah dago ini memang menyukai hal yang dapat memacu adrenalin naik.

\subsection{Sendi Gumilang Trianjaya}

Sendi Gumilang Trianjaya atau yang sering dipanggil "Dower" ini lahir di Bandung pada tanggal 1 November 1987. Sendi merupakan lulusan dari SD Korpri 2, lalu tingkat SMP di SMPN 1 Baleendah, SMAN 1 Banjaran dan meneruskan studinya di Universitas Pasundan (UNPAS). Setelah setengah perjalanan di UNPAS, Sendi akhirnya memutuskan untuk perpindahan kuliah ke Sekolah Tinggi Ilmu Komunikasi (STIKOM) Bandung dengan mengambil konsentrasi Broadcasting sampai saat ini.

\section{Pengalaman Hidup Pemakai Kaos Kalam}

\subsection{Pengalaman Hidup Soni Sonjaya}

Dalam syiar melalui pemakaian kaos Kalam ini, soni bersama teman- temannya pernah merasa diawasi oleh beberapa orang di beberapa mall di kota Bandung ini, mulai dari BIP, Ciwalk dan mall-mall lainnya. Banyak orang yang cara melihatnya itu dengan sinis, ada juga yang terheran-heran, ada yang merasa agak takut. Banyak sekali ragam reaksi yang didapatkan oleh Soni ketika memakai kaos Kalam ini khususnya di tempat-tempat publik seperti mall dan tempat lainnya.

\subsection{Pengalaman Hidup Heri}

\section{Firmansyah}

Seorang Heri yang sering memakai kaos Kalam ini kemanapun dan dalam kegiatan apapun juga sering mendapatkan berbagai reaksi yang beragam, mulai dari reaksi istrinya yang karena frekuensi pemakaian yang sering oleh suaminya itu sehingga berkata kepada suaminya seperti tidak ada baju yang lain lagi yang bisa dipakai. Menanggapi hal ini Heri merasa bahwa dengan dirinya memakai kaos Islami Kalam ini menciptakan suatu kebanggaan, pengakuan dan bukti bahwa dirinya adalah seorang muslim walaupun kebanggan itu tidak hanya dibuktikan dengan seperti ini saja tapi inilah bukti yang diperlihatkan oleh seorang Heri walaupun nantinya akan ada tanggapan ke diri Heri apakah seorang yang garis keras, fanatik atau apapun tapi kembali lagi ke diri masingmasing bahwa seorang Heri sangat bangga dengan kaos ini dan pembuktian bahwa dia bangga menjadi muslim.

\subsection{Pengalaman Hidup Agus}

\section{Purwanto}

Puncaknya adalah ketika Agus sedang membawa keluarganya jalanjalan ke Cihampelas Walk (Ciwalk). Ketika itu Agus sedang ingin ke toilet, maka pergilah Agus dengan keluarganya untuk ke toilet terlebih dahulu. Setelah keluar dari toilet dan 
sedang menunggu istrinya keluar toilet, tiba-tiba ada seorang wanita yang tergolong dewasa atau ibu-ibu menyapa dan langsung bertanya kepada Agus mengenai kenapa Agus memakai tulisan Arab ke toilet karena sepengetahuannya tidak boleh memakai tulisan Arab ke dalam toilet. Ketika mendapati pertanyaan seperti itu, Agus Purwanto pun menanyakan balik ke wanita itu mengenai arti dari tulisan Arab yang sedang dipakai oleh Agus yang memang pada saat itu Agus sedang memakai kaos kalam dengan desain tulisan Arab yang bertuliskan pada bagian depannya لِلِلْعالَمِينَ رَخْمَةًَ" dan dibawahnya terdapat kalimat dalam bahasa inggris bertuliskan "Bless For The Universe".

\subsection{Pengalaman Hidup Sendi}

\section{Gumilang Trianjaya}

Sama seperti yang dirasakan oleh informan lainnya, Sendi juga mendapatkan perhatian yang lumayan banyak dari lingkungan dimana ia berada ketika memakai kaos Kalam tersebut. Banyak respon yang didapatkan baik dari teman dekat sampai dengan orang yang tidak kenal dengan seorang Sendi. Respon paling banyak yang didapat adalah lebih kepada ekspresi dari lingkungan yang mereka seakan memperhatikan desain kaos yang sedang Sendi pakai. Mereka seakan penasaran dengan isi kaos dan pesan apa yang ingin disampaikannya melalui desain ini. Selain itu tidak sedikit juga pujian dan ekpresi positif yang tentu saja baik yang ditimbulkan oleh orang-orang disekitarnya, baik yang berbicara langsung ataupun yang hanya jelas tersirat melalui mimik muka dari orang-orang yang memperhatikannya.

\section{Motif Pemakai Kaos Islami Distro Kalam Bandung}

\subsection{Motif Pengingat dan Pembatas}

\section{Diri}

Kita sebagai manusia memang diciptakan oleh Allah SWT secara sempurna, hanya iman dan sikap kitalah yang masih jauh dari kata sempurna. Maka dari itulah Soni dengan pengalaman hidupnya dulu yang masih belok-belok dari ajaran agama Islam setelah bertemu dengan kawankawannya merasa ada sesuatu yang salah dalam kehidupan yang dia jalani, sampai akhirnya bertemu dengan Ombat sang vokalis dari band metal Tengkorak yang dengan bangga memakai kaos yang saat itu bertuliskan One Finger Movement atau gerakan satu jari yang maksudnya adalah tauhid kepada Allah SWT.

Mendapatkan reaksi dari banyak orang baik yang dikenal ataupun tidak dan beragam ekspresi serta tanggapan membuat kita semakin belajar dari kaos Kalam ini. Ketika ada yang bertanya ini dan itu dalam pemakaian kaos Kalam ini, maka kita pun secara tidak langsung dituntut untuk mengetahui apa yang sedang dipakai ini serta maksud dan tujuannya apa. Ketika orang memakai jas dan celana katun hitam tentu mempunyai maksud dan tujuan tersendiri serta orang yang memakai pun tahu maksud dan kenapa harus berpakaian seperti itu, itu pun berlaku bagi semua pakaian yang dipakai oleh orang-orang.

Tidak hanya sikap tapi akhlak juga ikut terbatasi dengan sendirinya ketika memakai kaos Kalam ini, tidak mungkin ketika memakai kaos Kalam ini kita akan berbicara dengan teman kita dengan bahasa yang kurang enak didengar atau kasar, pasti kita akan memiliki setidaknya rasa malu bahwa ketika itu kita sedang memakai kaos yang bernilaikan asas-asas nilai Islami. 


\subsection{Motif Syiar atau Dakwah Secara}

\section{Tidak Langsung}

Dengan orang lain melihat kaos Kalam ini maka secara otomatis orang lain pun minimal akan membaca apa yang ada di kaos Kalam ini. Dengan membaca minimal hatinya sedikit banyak terketuk mengenai arti atau makna dari desain yang disajikan dalam kaos Kalam ini. Terlepas apakah orang lain yang membaca itu menjadi terjaga sikap dan akhlaknya itu kembali lagi kepada keinginan atau hati dari orang yang melihat desain kaos Kalam itu sendiri.

Dakwah itu pasca Nabi Muhammad SAW menjadi tugas yang harus dilanjutkan oleh umatnya, terlepas mengenai bentuk dan jenis dakwah yang dilakukannya. Sebagian ada yang memang melakukan bentuk dakwah dengan menceramahi atau menasihati orangnya secara langsung, ada yang melalui tindakan individu sehingga orang lain yang melihatnya akan merasa ingin meniru kepada kebaikan, ada juga lewat campuran kesenian dengan mencampurkan seni suatu daerah dengan isi yang dibumbui oleh ajaranajaran agama Islam seperti yang dilakukan oleh salah satu dari Wali Songo yaitu Sunan Bonang yang melalui kesenian wayang serta musik gamelan.

Kembali lagi kepada karakter setiap orang yang berbeda baik itu muslim ataupun non muslim, cara yang lembut merupakan cara yang paling baik dengan tidak merugikan atau menyakiti hati orang lain sehingga yang asalnya niat baik menjadi dianggap tidak baik oleh orang tersebut. Ketika ada cara yang baik yang bisa ditempuh maka harus dengan cara itu terlebih dahulu. Ketika Nabi dakwah pun dengan cara pendekatan yang persuasif terlebih dahulu, tidak langsung pada perang atau cara yang keras lainnya.
Perang menjadi opsi terakhir yang dilakukan demi memerangi kemurtadan pada waktu dahulu. Begitu pun dengan sekarang maka hal sama harus dilakukan yaitu dengan pendekatan yang tidak menyinggung perasaan orang lain khususnya dalam ajakan atau nasihat dalam agama.

\subsection{Motif Presentasi Diri}

Bukan berarti iman yang memakai kaos tersebut lebih tinggi daripada yang tidak memakai tapi lebih kepada presentasi diri orang tersebut yang memakai kalam tersebut penuh dengan rasa kecintaan dan kebanggan. Bagaimana pun pemakaian pakaian baik itu karena pakaian tersebut sesuai dengan karakter atau keinginan dirinya atau mempunyai maksud tertentu dimana ada alasan dibalik pemakaian suatu pakaian dalam hal ini dicontohkan seperti kaos Kalam ini.

\section{Makna Kaos Kalam Di Kalangan Pemakai}

Makna Kalam sendiri menurut Soni adalah khususnya sebagai pengingat serta pembatasan untuk diri sendiri, baik dalam sikap kita ataupun dari hati atau niatan kita. Menghindarkan diri dari perbuatan yang buruk serta tercela, karena merasa malu pada kaos yang kita pakai sendiri sehingga niatan atau sikap kita yang buruk itu tidak jadi kita lakukan. Syiar Islam pun menjadi salah satu makna yang hadir dalam kaos kalam ini karena melalui desain yang ada pada kaos ini setidaknya juga dapat terlihat dan terbaca oleh orang-orang yang ada di sekitar kita, apakah itu mempengaruhi orang lain ataupun tidak itu tidak jadi masalah, karena hanya Allah SWT lah yang dapat membolak-balikkan hati manusia.

Banyak orang yang merasa malu atau bahkan menyembunyikan identitas 
muslimnya, agama Islam menurut Heri hanya tercantum di KTP saja tapi belum masuk ke dalam pergaulan sosial kehidupan bermasyarakat. Tidak hanya baju koko dan peci saja yang dijadikan identitas muslim tapi memakai kaos Islami seperti Kalam juga merupakan pembuktian bahwa tidak hanya mencirikaan sebagai seorang muslim tapi juga unsur pengingat atau syiar.

Penyampakaian syiar atau pengingat yang disalurkan melalui non verbal ini apakah disadari atau dipahami oleh orang lain atau tidak disadari bukanlah masalah utama menurut Agus Purwanto, karena yang berkuasa terhadap pemberian hidayah itu hanyalah Allah SWT. Sebagai manusia hanya berusaha tanpa mengganggu atau memaksakan kehendak, Islam itu damai dan tidak memaksa jadi jangan menjadi hal seperti itu.

Semua berawal dari dalam diri terlebih dahulu karena Sendi menuturkan belum memiliki kapasitas dan ilmu secara khusus untuk lebih memberikan pengingat untuk orang lain, walaupun orang lain bisa menganggap atau merasa teringatkan setelah melihat kaos Kalam yang sedang dipakainya ini. Menjadi lebih menjaga diri dari hal-hal yang jelek ketika memakai kaos Islami dan membuat hal yang lainnya menjadi ikut terdorong kepada kebaikan seperti bahan obrolan bersama teman-teman yang asalnya membahas apapun baik itu yang positif ataupun hal yang berbau negatif. Namun ketika memakai kaos Kalam ini menjadi obrolan yang disajikan baik dari dalam pribadi ataupun lingkungan menjadi hal-hal yang baik saja bahkan membahas seputar agama yang memiliki nilai manfaat yang besar.

\section{Simpulan dan Saran}

Berdasarkan hasil temuan penelitian dan analisis hasil penelitian, maka dapat ditarik simpulan, sebagai berikut:

1. Dari serangkaian wawancara yang dilakukan oleh peneliti kepada para pemakai kaos Islami distro Kalam Bandung ini terungkap bahwa motif mereka memakai kaos Kalam adalah pengingat dan pembatas diri. Kaos Kalam dirasakan oleh pemakai sebagai suatu sarana pengingat dan pembatas diri yang sesuai untuk sikap dan akhlaknya. Kaos Kalam menjadi sarana pengingat dan pembatas diri karena selalu dipakai oleh pemakai kemana pun pemakai pergi sehingga dengan dikenakannya menjadi terasa mengingatkan diri pemakai untuk bersikap yang dianjurkan atau setidaknya jauh dari hal-hal yang tidak baik. Tidak hanya menjadi pembatas diri, pemakaian kaos Kalam ini juga menjadi pengingat secara khusus untuk dirinya sendiri dan secara umumnya untuk orang lain yang melihat kaos Kalam tersebut. Pemakai merasa bertanggung jawab memakai kaos Islami distro Kalam sehingga diaplikasikan rasa tanggung jawab tersebut dengan apklikasi sikap-sikap yang membatasi dari perbuatan yang tercela dan hal lainnya yang serupa. Ucapan juga menjadi teratur hanya dengan mengucapkan yang baikbaik saja dan dirasakan juga dengan kebiasaan yang baru dimana bahan obrolan menjadi sesuatu yang baik-baik dan terjaga serta lebih kepada membicarakan seputar hal-hal agama.

2. Berdasarkan hasil wawancara peneliti dengan para informan mengungkapkan bahwa motif 
dalam pemakaian kaos Kalam ini adalah syiar atau dakwah secara tidak langsung. Pemakai merasa sadar bahwa tugas dakwah pasca meninggalnya Nabi Muhammad SAW adalah menjadi tugas para umatnya di akhir zaman ini sehingga hal tersebutlah yang menjadi bahan pemikiran untuk mencari cara dakwah yang dapat dengan tepat diterima oleh publik. Melalui pemakaian kaos Islami distro Kalam ini pemakai merasa terwakilkan bagaimana mengemban tugas tersebut tetapi dengan tidak cara yang dapat membuat orang lain merasa digurui atau merasa diceramahi karena karakter atau sifat setiap orang berbeda dan mengantisipasi hal tersebutlah dengan cara memakai kaos Kalam ini menjadi terwakilkan. Orang sekitar yang melihat kaos Kalam merasa tidak sedang didakwahi karena proses berlangsungnya dakwah ini secara tidak langsung. Orang kadang tidak menganggap cara ini sebagai dakwah tapi justru inilah cara yang ampuh dan lembut dengan menuangkan nilai-nilai Islami atau pengingat lainnya melalui desain kaos Kalam ini. Yang merasa terilhami atau merasa diingatkan dengan kaos Kalam ini maka itulah tujuannya sedangkan yang tidak pun tidak akan merasa terganggu.

3. Merasa bangga terhadap keIslamannya walaupun tingkat iman yang masih dirasa belum maksimal dalam melakukan hal yang dianjurkan oleh Allah SWT tersebutlah yang menjadikan dengan memakai kaos Islami distro Kalam ini menjadi salah satu cara merasa bangga menjadi seorang muslim. Biasanya memakai baju koko dan peci adalah yang paling mencirikan hal tersebut, namun pada jaman sekarang memakai kaos dengan desain nilai-nilai Islami ataupun sebagai pengingat menjadi ciri yang menunjukkan bahwa dirinya adalah seorang muslim dan merasa bangga serta menunjukkannya walaupun di seluruh dunia sedang dilanda Islamophobia dimana khususnya di negara-negara barat menjadi anti atau bahkan langsung mencurigai hal-hal yang mencirikan muslim. Bahkan di kota Bandung Indonesia inipun yang merupakan mayoritasnya beragama Islam masih ada Islamophobia yang dilakukan oleh muslim sendiri dengan pengalaman yang diceritakan oleh informan Heri Firmansyah yang telah dibahas sebelumnya.

4. Hasil dari penelitian ini menemukan dan mengungkap bagaimana pemakai kaos memaknai pemakaian kaos Islami distro Kalam ini pada dirinya. Informan sepakat bahwa makna yang dimunculkan dalam pemakaian kaos Islami distro Kalam ini adalah sebagai sarana pemulihan sikap dan hati yang dicerminkan dalam pemakaian kaos Kalam. Rasa malu yang timbul jika hendak melakukan hal yang kurang baik ketika memakai kaos Kalam karena selain itu juga menjaga tanggung jawab pada diri sendiri dengan apa yang sedang dipakai.

5. Makna syiar Islam serta merasa ikut mengerjakan tugas kedakwahan yang dahulu dilakukan oleh Nabi Muhammad 
SAW. Melakukan tugas dakwah dengan cara halus dan tanpa seperti menggurui atau bahkan menasihati orang lain. Bahkan orang lain tidak merasa sedang didakwahi oleh pemakai namun kesadaran diri dari melihat desain dengan nilai Islami itulah dan ridho Allah SWT yang Maha membolak-balikkan hati manusia dengan kehendaknya.

Berdasarkan penelitian yang dilakukan, peneliti mengajukan saransaran sebagai berikut:

1. Masih sedikit jumlah distro yang mengembangkan atau mengaplikasikan nilai-nilai Islami pada desain di kaosnya masing-masing, sehingga disini peneliti memberikan saran khususnya kepada pelaku bisnis distro dan secara umumnya kepada masyarakat luas untuk lebih mengembangkan dan menciptakan desain distro yang di dalamnya dituangkan nilainilai Islami yang dapat dipertanggung jawabkan isi dan desain serta maknanya. Berbisnis sekaligus berdakwah serta membatasi sikap dan memberikan pengingat bagi diri sendiri dan umumnya orang lain dengan memakai kaos Islami merupakan hal yang sangat baik dari segi bisnis dan juga dari segi nilai Islami yang membantu dalam penyebaran nilai-nilai Islam yang saat kini mulai pudar meski di kalangan muslim sendiri. Tidak hanya diaplikasikan dalam desain kaos tetapi juga dapat mengembangkannya dalam produk yang lain sehingga akan lebih banyak variasi yang hadir.

2. Peneliti juga memberikan saran kepada pelaku bisnis yang sama- sama menciptakan atau menghadirkan desain distro dengan nilai-nilai Islami seperti distro Kalam ini untuk lebih memperbanyak desaindesainnya yang bersifat pengingat serta dengan tampilan desain yang simple tetapi mendalam terhadap makna yang dikandungnya.

3. Peneliti ingin memberikan saran kepada Pemerintah Kota Bandung dan kepada semua pihak yang dapat memberikan sarana kepada penggiat distro Islami seperti Kalam dan lainnya ini untuk lebih dikenal serta di publikasikan baik di lokal kota Bandung ataupun secara nasional serta membuat kaos Islami seperti ini menjadi tren untuk fashion lokal dan nasional karena mengandung banyak kebaikan selain faktor bisnis semata.

4. Bagi peneliti lain yang tertarik untuk mendalami penelitian yang hampir sama seputar pemaknaan kaos islami, peneliti memberikan saran untuk lebih menggalinya pada hal keefektifan dakwah secara tidak langsung melalui pemakaian kaos islami.

\section{Daftar Pustaka}

Alma, Buchari. 2007. Metode dan Teknik Menyusun Tesis. Bandung: Alfabeta.

Basrowi, dan Suwandi. 2008. Memahami Penelitian Kualitatif. Jakarta: Rineka Cipta.

Bungin, Burhan. 2009. Penelitian Kualitatif. Jakarta : Kencana.

Burgoon, Judee K., and Thomas Saine. 2003. Introductionto Nonverbal

Communication. Boston: Houghton Mifflin School 
Chaer, Abdul. 2007. Linguistik Umum. Jakarta: Rineka Cipta.

Danim, Sudarwan. 2002. Menjadi Peneliti Kualitatif. Bandung: Pustaka Setia.

Deddy Mulyana, Ilmu Komunikasi Suatu Pengantar, (Bandung: PT Remaja Rosdakarya, 2010)

Denzin, dan Lincoln. 2009. Handbook Of Qualitative Research. Terjemahan: Dariyanto, Badrus Samsul Fata, Abi, John Rinaldi. Yogyakarta: Pustaka Pelajar.

Ekman, dan Friesen. 1969. Emotions in The Human Face. Jakarta: Rineka Cipta.

Ekman, Friesen, Ellsworth. 1972. Emotions in The Human Face. Jakarta: Rineka Cipta.

Effendy, Onong Uchyana. 1994. Komunikasi Teori dan Praktek, Bandung

Effendy, Onong Uchyana. Ilmu Komunikasi Teori dan Praktek. (Bandung: PT Remaja Rosdakarya, 2009)

Durkheim, Emile. 1915. The Elementary Forms of the Religious Life. London: George Allen \& Unwin.

Goffman, Erving. 1967. Interaction Ritual.

Hamid, Farid. 2010. Disertasi Jilbab Sebagai Identitas Diri Dalam Kajian Komunikasi Artifaktual. Bandung: Universitas Padjadjaran.

Joseph T. Shipley, Dictionary Of World Literature, (New York: Littlefield, Adams \& Co, 1962)

Judy Pearson, Human Communication, (New York: Mc Graw Hill Companies, 2003)

Kant, Immanuel (2001). Religion and Rational Theology. Cambridge University Press.

Keraf, Gorys. 1994. Komposisi. Jakarta: Nusa Indah.

Knapp, Mark. 1978. Nonverbal Communication In Human
Interaction. NY: Holt, Rinehart \& Winston. Editions with Hall.

Kotler, Philip dan Kevin Lane Keller, Manajemen Pemasaran (Edisi Kedua Belas), Cetakan Ketiga, PT. Indeks, Jakarta, 2008.

Kridalaksana, Harimurti. 2001. Kamus Linguistik. Jakarta: Gramedia Pustaka.

Kuswarno, Engkus. 2009. Metodologi Penelitian Komunikasi Fenomenologi Konsepsi, Pedoman, dan Contoh Penelitian. Bandung: Widya Padjadjaran.

Lasswell, Harold. 1994. The Structure and Function of Communication in Society. Jakarta: Gramedia Pustaka.

Leathers, Dale. 1986. Successful Nonverbal Communication. Jakarta: Gramedia Pustaka.

Littlejohn, Stephan W, dan Foss, Karen A. 2009. Teori Komunikasi. Terjemahan: Daud, Afrianto dan Iva Izzati Putri. Jakarta: Salemba Humanika.

Mansoer Pateda, Semantik Leksikal, (Jakarta: Rineka Cipta, 2001).

Moleong, Lexy. 1991. Metodologi Penelitian Kualitatif. Bandung: Remaja Rosdakarya.

Moleong, Lexy. 2009. Metodologi Penelitian Kualitatif. Bandung: Remaja Rosdakarya.

Mulyana , Dedy. 2001. Metodologi Penelitian Kualitatif: Paradigma Baru Ilmu Komunikasi dan Ilmu Sosial Lainnya. Remaja Rosdakarya. Bandung.

Mulyana, Deddy. 2005. Ilmu Komunikasi: Suatu Pengantar. Bandung: Remaja Rosdakarya.

Mulyana, Deddy dan Solatun. 2007. Metode Penelitian Komunikasi. Bandung: Remaja Rosdakarya.

Nasution. 2003. Metode Research, Jakarta : PT. Bumi Aksara.

Nugroho, Riant. 2004. Komunikasi Pemerintahan. Jakarta: Elex Media Komputindo. 
Nurhayati, Siti. 2011. Tesis Konstruksi Makna Kerudung. Bandung: Pascasarjana Universitas Padjadjaran

Ogden, and Richards. 1972. The Meaning. London: Routledge \& Kegan

Rakhmat, Jalaluddin. 2009. Psikologi Komunikasi. Bandung: Remaja Rosdakarya.

Ruben, Brent D,Stewart, Lea P. 1998. Communication and Human Behaviour. USA:Alyn and Bacon

Ruslan, Rosadi. 2003. Metode Penelitian PR dan Komunikasi. Jakarata : PT. Raja. Grafindo Persada

Saussure, Ferdinand de. 1994. Pengantar Linguistik Umum. Yogyakarta: Gadjah.

Sendjaja, S. Djuarsa. 1994. Teori Komunikasi. Jakarta: Universitas Terbuka.

Shovmayanti, Noor Afy. 2012. Konstruksi Makna Batik Sebagai Fashion. Bandung: Universitas Padjadjaran.

Sugiyono. 2005. Metode Penelitian Kuantitatif Kualitatif dan R\&D. Bandung: Alfabeta.

Sugiyono. 2011. Metode Penelitian Kuantitatif Kualitatif. Bandung: Alfabeta.

Widyosiswoyo, Hariwijaya Soewandi (1991). Ilmu Alamiah Dasar. Ghalia Indonesia, Jakarta Timur.

Wiryanto. 2004. Pengantar Ilmu Komunikasi. Jakarta: PT. Grasindo. . 2007. Islam

Basics: About Islam and American Muslim, Council on AmericanIslamic Relations (CAIR).

adinfopuri.blogspot.com/2010/11peluan g-bisnis-clothing-distro.html 